\title{
DA AUTOBIOGRAFIA AO TESTIMONIO: AS REPRESENTAÇÕES SI E DA HISTÓRIA EM MEMORIAS DE UN SOLDADO DESCONOCIDO, DE LURGIO GAVILÁN SÁNCHEZ
}

\author{
Lorena Carvalho dos Reis ${ }^{1}$
}

Resumo: Memorias de un soldado desconocido. Autobiografía y antropología de la violencia (2012) é uma obra que trás à tona o relato de vida de Lurgio Gavilán Sánchez, um cidadão peruano que participou diretamente do maior conflito armado do seu país, a Guerra Interna do Peru (1980-2000). Tendo em vista o contexto de produção da obra, seu gênero e as dúvidas teóricas suscitadas tanto pelo testimonio quanto pela autobiografia, este artigo visa analisar as estratégias de representação de si e da história no texto autobiográfico de Gavilán, a fim de contribuir para os estudos da memória e do testemunho nessas vertentes literárias.

Palavras-chave: Guerra Civil no Peru; autobiografia; testimonio; identidade social.

Abstract: Memorias de un soldado desconocido. Autobiografía y antropología de la violencia (2012) is a book that brings to light the life story of Lurgio Gavilan Sanchez, a citizen of Peru who participated directly in the most expressive armed conflict in their country, the civil war of Peru (1980-2000). Given the production context of this work, gender and theoretical concerns raised both by the testimony as the autobiography; this article aims to analyze the strategies of self-expression and representations of history in Gavilan's autobiographical text, in order to contribute to the memory and testimony studies in these literary aspects.

Keywords: Civil war in Peru; autobiography; testimony; social identity.

\footnotetext{
${ }^{1}$ Mestranda em Estudos Literários pela Universidade Federal de Minas Gerais (UFMG). Bolsista Capes. E-mail: lorenadosreis@gmail.com.
} 


\section{Introdução}

Publicado em 2012, Memorias de un soldado desconocido. Autobiografía y antropología de la violencia é uma obra que trás à tona o relato de vida de Lurgio Gavilán Sánchez, um cidadão peruano que participou diretamente do maior conflito armado do seu país, a Guerra Interna do Peru. ${ }^{2}$ Ao longo das mais de 170 páginas do livro, Gavilán compartilha suas memórias de criança campesina que, aos 12 anos de idade, se uniu às colunas terroristas do Sendero Luminoso, em aventuras pelas selvas peruanas, num processo de amadurecimento precoce e intenso. Mais que o relato de uma vida, a obra de Gavilán pretende ser, como indica o título, uma denúncia antropológica sobre a violência em seu país.

Gavilán estrutura o relato de sua experiência em quatro partes: seu envolvimento com o movimento terrorista Sendero Luminoso, sua estada no exército peruano, sua vida em um convento franciscano e o retorno à sua comunidade de origem em tempos de paz. Assim, vale ressaltar que esta autobiografia oferece, ao contrário de visões unívocas sobre esse conflito armado, uma perspectiva múltipla para análise deste. Ao ser embasado por vivências transitórias em espaços diversos, ela é uma janela para o estudo do passado de três das mais importantes instituições desse período: o movimento de guerrilhas, o Estado e a religião franciscana.

No primeiro capítulo, "En las filas de Sendero Luminoso", Gavilán conta detalhes da sua vida nos anos oitenta. Aos 12 anos, vivia uma vida simples e tranquila, no aconchego da companhia de seus pais e do campo. Tudo muda, segundo Gavilán, quando seu irmão mais velho decide unir-se ao movimento do Sendero e Gavilán, em 1982, segue seus passos. Advogando a favor de valores comunistas, como a tomada do poder pelo povo, o fim da exploração

\footnotetext{
${ }^{2}$ A Guerra Interna no Peru (1980-2000) foi um conflito armado ocorrido entre o Estado Peruano e o grupo terrorista Sendero Luminoso (PCP-SL). Durante os vinte anos de conflito, estima-se que o número de vítimas gire em torno de 70.000 mortos. O conflito mais sangrento na história do Peru afetou principalmente a população andina, sendo esta, em sua maioria, camponeses das localidades mais pobres do país e falantes do quéchua.
} 
do homem pelo o homem, o Sendero Luminoso foi uma organização fortemente embasada pela retórica marxista e maoísta de Abimael Guzmán Reynoso, seu principal mentor. A princípio, este grupo terrorista logrou aliciar e convocar centenas de crianças e jovens para a luta armada. ${ }^{3}$ As barbáries cometidas pelo SL contaram com requintes de crueldade que, até os dias atuais, são difíceis de abarcar. ${ }^{4}$ Escravidão sexual de mulheres, extermínio de homossexuais, esquartejamentos em massa de militares: são estas apenas algumas das estratégias de um movimento que, num primeiro momento, seduziu milhares de cidadãos a unir-se na luta pela melhoria de vida no país. ${ }^{5}$ Nas filas do SL, o narrador de Memorias de um soldado desconocido relata as diversas práticas cotidianas de doutrinação das quais participou, juntamente com outros milhares de meninos recrutados por esse grupo terrorista. Além dessas informações, Gavilán também conta como, em 1983, escapou da morte e teve sua vida poupada pelo inimigo, numa emboscada frustrada aos soldados do exército.

A partir desse momento, Gavilán passa a lutar no exército e conta, no capítulo "Tiempos en el cuartel militar", todo o apoio estatal que recebeu para finalizar seus estudos e as instruções militares que ganhou para combater as

\footnotetext{
${ }^{3}$ A princípio as aglomerações do SL se concentravam nas regiões serranas do Peru. Ao longo dos anos oitenta o grupo ganha força, com a adesão de milhares de "comuneros", camponeses insatisfeitos com as políticas governamentais de utilização da terra, que se uniram à propaganda desse movimento que dizia "defender os direitos do povo". Ao longo dos anos noventa o SL chega às regiões da selva peruana, mimetizando-se às comunidades que ali se encontravam. Seu objetivo primeiro: chegar às escolas locais, no intento de recrutar jovens e crianças para a luta armada. É nesse contexto de Lurgio Gavilán Sánchez testemunha e relata grande parte das suas memórias.

${ }^{4}$ Além das diversas memórias escritas, cantadas e filmadas sobre as vítimas do conflito interno no Peru, destaco aqui a singularidade do trabalho de Edilberto Jiménez, antropólogo e artista da cidade de Ayacucho, que retrata na forma de retábulos o horror sofrido pela população peruana durante essa guerra. Cf.: "Los retablos de Edilberto Jiménez sobre la violencia política". Disponível em: <https://lamula.pe/2012/05/18/los-retablos-de-edilberto-jimenez-sobrela-violencia-politica/leolamas/>. Acesso em: 24 out. 2015.

${ }^{5}$ A respeito da situação precária de grande parte da população campesina peruana nos anos 1970, como a insatisfação com a reforma agrária militar, as controvérsias frente às medidas governamentais sobre o uso da terra, as relações entre o índio e os donos das terras, etc. Cf.: MALLON, Florencia. ¿Crónica de un sendero anunciado? Velasco, Vanguardia Revolucionaria y "presagios luminosos" en las comunidades indígenas de Andahuaylas. In: STERN, Steve (ed.). Los senderos insólitos del Perú: Guerra y sociedad, 1980-1995. Lima: IEP/UNSCH, 1999.
} 
ações do Sendero. Quando combate nesse lado do conflito, Gavilán relata seus anos como militar, os ritos de passagem entre os soldados, as estratégias de combate ao terrorismo, o medo da população ao deparar-se com o exército etc. Nessa etapa do relato, o narrador também denuncia os excessos cometidos pelo exército peruano: a matança de civis, os estupros coletivos, a ocultação de cadáveres, entre outros crimes de Estado:

\begin{abstract}
Essa vez, em 1985, na base de São Miguel os soldados decidiram matar a todos os prisioneiros, pois o período das inspeções se aproximava. Trouxeram as mulheres para a quadra e todos abusaram delas. Elas choravam: - não nos matem, disseram. Eu também estava assustado. Por volta da meia noite levaram as mulheres ao campo onde sempre cumpríamos a nossa formação. Todos foram presenciar a morte delas. A vala já estava cavada. Dois tiros soaram em uníssono e elas caíram mortas (GAVILÁN, 2012, p. 113; tradução minha). ${ }^{6}$
\end{abstract}

Após quase dez anos de luta pelo lado do governo peruano, Gavilán passa por outro momento limítrofe com a morte. Em 1993, ele é atingido por sendeiristas durante um conflito direto e é internado com uma hemorragia interna. Durante sua internação na base militar de Viviana, e após várias conversas com as freiras que o ajudaram em sua recuperação, ele conhece missionárias da "Jesús Verbo y Víctima" e simpatiza com a causa sacerdotal. Em 1995, Gavilán ingressa no convento franciscano, na esperança de ter uma vida diferente da que vivia até então, almejando experiências mais espirituais e pacíficas. No entanto, Gavilán se depara, uma vez mais, com um sistema cujas relações de poder e de submissão era semelhante ao que ele já havia experimentado no SL e, posteriormente, no exército peruano. No penúltimo

\footnotetext{
6 "Esa vez, 1985 en la base de San Miguel, decidieron matar a todos los que estábamos como prisioneros, pues venía la inspección. Trajeron a las mujeres a la cuadra, y todos abusaron de ellas. Ellas lloraban; "no nos maten", dijeron; yo estaba también asustado. Como a la media noche llevaron a las mujeres al campo donde siempre nos formábamos. Todos fuimos a presenciar su muerte. Ya estaba cavada la fosa. Dos tiros sonaron al unísono y ellas cayeron muertas" (GAVILÁN, 2012, p. 113).
} 
capítulo, intitulado "Tiempos en el convento franciscano", o narrador estabelece uma relação entre todas as instituições pelas quais passou. ${ }^{7}$

Após vários anos nesse convento, Gavilán começa a formular outros planos para sua vida, como voltar ao seu povoado de origem, ter uma família e trabalhar. Contudo, Gavilán deixa a vida sacerdotal e ingressa na universidade para estudar antropologia. É com "Veinte años después, recorriendo las huellas del pasado" que Gavilán finaliza seu relato, narrando o quão difícil foi o processo de retorno ao seu povoado de origem. Após décadas de distanciamento do seu país, Gavilán logra consolidar-se na profissão de antropólogo e resolve, por fim, percorrer os caminhos pelos quais anteriormente havia transitado com o SL e o exército peruano.

Nesse sentido, diante das vivências fragmentadas, diversas e contraditórias de Gavilán nota-se que sua narração conforma um corpus pertinente para as análises da memória, do testemunho, bem como da representação de si e da história. Assim, este trabalho objetiva analisar as estratégias de organização das memórias de Gavilán, a compreensão de si e do seu testimonio dentro de uma contingência histórica - e a imposição desta sobre sua trajetória -, bem como os modos como esse narrador realiza a continuação de sua vida por meio da escrita.

\section{Autobiografia, ou a estrutura de uma vida}

Pois memórias e autobiografias são substitutas dos espelhos. Se estes, metálicos e implacáveis, assinalam o desgaste dos traços, o torpor dos olhos, a redondeza do ventre, fechamo-nos contra a maldade dos espelhos e procuramos nos rever no que fomos, como se o percurso da antiga paisagem nos capacitasse a nos explicar ante nós mesmos (COSTA LIMA, 1985, p. 244).

\footnotetext{
${ }^{7}$ Para estabelecer esta comparação, Gavilán conta: "Meu "pai" maestro era igual a um oficial do exército. Às cinco da manhã nos levantávamos para os exercícios. Sendo estes não espirituais, mas de fortalecimento das pernas, para poder cumprir as missões franciscanas. Corríamos durante 15 minutos por volta do claustro quando ainda não havia amanhecido, enquanto os frades seguiam dormindo. [...] os religiosos viviam em comunidade, não era possível ter esposas. Além do mais, de tempos em tempos transitávamos de convento em convento, como os militares e os do Sendero Luminoso" (GAVILÁN, 2012, p.134; tradução minha).
} 
Como propõe Philippe Lejeune (1975), a especificidade da autobiografia se dá a partir da identidade entre narrador e autor. Assim, por meio de um "pacto autobiográfico" firmado com o leitor, o texto declara-se como "esta é uma autobiografia". A vida individual, temática que embasa a narrativa autobiográfica, é um retrospecto dos eventos significativos da vida de um sujeito. Dito isso, a partir de Lejeune (1975) e dos seus estudos sobre a autobiografia, ressalta-se 0 intento do autor em tornar comunicáveis suas vivências e experiências fragmentadas ao público. ${ }^{8}$

A respeito do gênero autobiográfico, é interessante observar a estratégia de auto-representação adotada por Gavilán no texto aqui analisado. Nos três primeiros capítulos, Gavilán narra sua vida na primeira pessoa do plural e somente ao final da obra, na parte IV "Veinte años después, recorriendo las huellas del pasado", é que se vale da primeira pessoa do singular. Para Gavilán, tudo o que é testemunhado o é de forma coletiva. Os crimes no SL, os excessos dos militares, as meditações no convento. O "eu" é, ao longo de todo o relato, indissociável de um "nós".

Como propõe Michael Pollak (1992) em "Memória e identidade social", quais seriam os dados que constituem a memória, seja ela de caráter individual ou coletiva? Segundo o autor, os acontecimentos vividos diretamente ocupariam o primeiro lugar nessa escala, e estes são seguidos pelos episódios "vividos por tabela", que se relacionam a um determinado grupo ou coletividade à qual um indivíduo acredita pertencer. Ainda segundo Pollak (1992), as preocupações individuais e políticas de um determinado período mostram que a memória é um fenômeno construído, social e de caráter coletivo. Nesse sentido, é possível considerar a utilização do pronome "nós" em Gavilán como estratégia de vinculação da experiência narrada às instituições das quais ele

\footnotetext{
${ }^{8}$ Este aspecto pragmático sublinha, uma vez mais, a importância do leitor da construção da obra, como observa Costa Lima (1985, p. 307 apud ALBERTI, 1991, p.13): Na medida em que exige do escritor o esforço de tornar inteligível para os outros sua experiência "fragmentada". Caso contrário, se teria, no limite da busca de sentido para a própria vida, um "veto à comunicação", uma "radicalização do autobiográfico, implicando a impossibilidade de partilhar os seus significados" (Costa Lima, 1985, p. 307), uma vez que só o autor seria capaz de significar-se a si mesmo, não dando condições ao leitor de "partilhar o que ali se oferece". (ALBERTI, 1991, p.13)
} 
fazia parte: Sendero, exército e igreja. ${ }^{9}$ Dessa forma vale sublinhar, também, a recorrência aos elementos da cosmovisão andina que revelam, através do testimonio de Gavilán, as relações que ele manteve com uma determinada realidade e com os sistemas culturais coexistentes de determinada sociedade, no caso a coletividade campesina da qual ele foi partícipe. É nesse sentido que se pode analisar, também, o pragmatismo da autobiografia de Gavilán. Para além de uma autobiografia, Memorias de un soldado desconocido pretende ser um relato antropológico da violência. Assim, Gavilán desenvolve uma série de estratégias narrativas que vão ao encontro desse projeto. No Capítulo I, intitulado "En las filas de Sendero Luminoso", Sánchez Gavilán apresenta um mapa político de Ayacucho, a fim de delinear as rotas que percorreu junto aos militantes do Sendero. Assim, é possível observar, uma vez mais, o caráter pragmático dessa narrativa. $O$ autor também tem o cuidado de fornecer notas de rodapé com os termos em quéchua utilizados no seu texto, bem como traduções ao espanhol de várias expressões linguísticas andinas e referências ao informe da Comissão da Verdade no Peru.

Tendo em vista o esquema proposto por Helmut Galle (2006) em "Elementos para uma nova abordagem da escritura autobiográfica", é possível dividir o processo narrativo de Gavilán da seguinte maneira: 1) a formação do sujeito: Capítulos I, II e III; 2) a crise sofrida / 3) assimilação da crise e a reconfiguração da identidade: Capítulo IV. Na última parte do relato, é interessante observar a mudança no estilo narrativo de Gavilán. Para além das mudanças verbais e da pessoa do discurso, Gavilán adota um tom mais subjetivo na tessitura de seu testemunho. Ele já não testemunha como um soldado, testemunha como um ex-campesino. Ao relatar a dor que sente ao deparar-se com os fantasmas do seu passado, o narrador evidencia a carga traumática das suas memórias de guerra. Sendo estas, até então, não rastreáveis no texto:

\footnotetext{
${ }^{9}$ Em entrevista ao programa Presencia Peruana, no canal Televisión Peruana, Gavilán é perguntado sobre sua identidade de soldado, e responde à entrevistadora: "- Eu sou um soldado". Cf.: "14.12.12. Memorias de un soldado desconocido, autobiografía y antropología de la violencia". Disponível em: <https://www.youtube.com/watch?v=si8L3zbg2tU\&spfreload=10>. Acesso em: 12 out. 2015.
} 
O sol surge no oriente e eu me vejo cada vez mais heterogêneo, às vezes penso no fascinante que é ser o outro. Sinto que o tempo ficou atravessado na minha vida, engasgado, e essa lembrança me dói e dói. Sinto nos braços, nas pernas, no coração. Sinto que a lembrança se alimenta como as pulgas ou os piolhos brancos que se alimentaram do meu sangue quando eu, clandestino, caminhava com o fuzil nas mãos, lendo a bíblia de Mao Tse-Tung (GAVILÁN, 2012, p. 164 ; tradução minha). ${ }^{10}$

Quando confessa ter fascínio em ser "o outro", Gavilán pode ter se dado conta da impossibilidade da inteireza do seu eu-narrador e realiza um deslocamento, "como o personagem, para o plano da construção: passa a ser uma imagem do autor, construída e gravada nas linhas do livro" (ALBERTI, 1991, p. 15). O "eu para si" e o "eu para os outros" parece sofrer uma tensão nessa etapa do relato e sublinha, uma vez mais, que a construção da identidade não se realiza sem a presença de ambiguidades. A questão do "outro" pode ser entendida aqui como autocrítica da tessitura autobiográfica, remetendo à ilusão de inteireza de que fala Alberti (1991): “Assim, é apenas no espaço limitado da semelhança entre aquilo que «é» e aquilo que se cria que o escritor de autobiografia pode imaginar-se outro de si mesmo" (ALBERTI, 1991, p. 10).

\section{Testimonio e autobiografia: pontos de contato}

Em estudo intitulado "Documentalismo y ficción: Testimonio y narrativa testimonial hispanoamericana en el siglo XX", Mabel Moraña (1997) apresenta, entre outras reflexões, uma série de características relativas ao testimonio, e suas especificidades narrativas. Valendo-se da definição oferecida por

\footnotetext{
10 "Aparece el sol por el oriente y viéndome cada día heterogéneo, a veces pienso en lo fascinante que es ser el otro. Siento que el tiempo se atraganta en mi vida y este recuerdo me duele y duele; siento en los brazos, en las piernas, en el corazón. Siento que el recuerdo se alimenta como las pulgas o los piojos blancos que se alimentaron de mi sangre cuando clandestino caminaba con fusil en mano, leyendo la biblia de Mao Tse -Tung" (GAVILÁN, 2012, p. 164).
} 
Berveley y Zimmerman, Moraña (1997) caracteriza o testimonio como uma forma de "narrativa épica, popular-democrática, e não fictícia, onde a voz narrativa testemunhal corresponde ao protagonista e à testemunha dos fatos narrados. [...] Ele representa um setor ou classe social, e é distinto da individualidade do herói problemático do romance burguês" (MORAÑA, 1997, p. 5; tradução minha). ${ }^{11}$ Nesse sentido, a questão da identidade entre autor narrador no pacto autobiográfico configura-se também no testimonio, recordando o que comenta Galle (2006) sobre a filiação entre autobiografia e testemunho no século $X X$, e seus debates centrais na atualidade. ${ }^{12}$ Dessa forma, a proposta de pensar as relações entre testimonio e autobiografia a partir do texto de Gavilán é, também, repensar "dúvidas teóricas sobre a representação, o sujeito e a vida" (GALLE, 2006, p. 78).

A relação entre testimonio e luta popular torna-se essencial, segundo Moraña (1997), para a compreensão dessa modalidade narrativa como um exercício popular e democrático, ligado diretamente às situações políticas e econômicas da região hispano-americana. ${ }^{13}$ Dito isso, em primeiro lugar vale ressaltar o valor do testimonio como elemento de denúncia. ${ }^{14}$ Esse aspecto, fundamental para o estudo do texto de Gavilán, se configura já a partir do título, uma vez que o autor anuncia, de antemão, que sua autobiografia se propõe, também, "um estudo antropológico da violência em seu país". O testimonio de Gavilán configura um relato duplo, pois ao mesmo tempo em que conta a história de um representante dos poderes do período - um guerrilheiro, um

\footnotetext{
11 "[...] una forma de narrativa épica, popular-democrática y no-ficticia, donde la voz narrativotestimonial (correspondiente ya al protagonista ya a un testigo de los hechos narrados) se expresa a través de una fuerte presencia textual, y representa a un sector o clase social, apartándose así de la individualidad del "héroe problemático" de la novela burguesa." (MORAÑA, 1997, p. 5)

12 Segundo o autor, esta relação é essencial para os debates atuais acerca das "categorias como ficcionalidade, representação e autenticidade." (GALLE, 2006, p. 77)

${ }^{13}$ Nesse sentido, e como ressalta a autora, os testimonios referentes à luta armada e aos movimentos de libertação nacionais são os tipos mais populares de testimonios ao redor de todo o continente.

${ }^{14}$ A respeito da "continuidade da opressão" no testimonio, vale conferir as reflexões propostas por Márcio Seligmann- Silva (2001) em: SELIGMANN-SILVA, Márcio. "Zeugnis" e "Testimonio": um caso de intraduzibilidade entre conceitos. Letras, n. 22: "Literatura e Autoritarismo", Santa Maria, RS, pp. 121-130, jan. / jun. 2001.
} 
soldado, um monge -, também sintetiza a vivência de um campesino que com apenas 12 anos de idade foi persuadido a se tornar uma máquina de guerra. Ou seja, além de um representante do poder, Gavilán também é uma vítima e um sobrevivente.

Como observa Moraña (1997), um dos aspectos mais instigantes no estudo do testimonio refere-se à construção do sujeito que testemunha, o eunarrador. Segundo a autora, "o eu-narrador do testimonio é uma extensão da coletividade, mas não uma substituição desta", pois ele propõe "uma operação estratégica de representação [...] de uma vivência coletiva de caráter não individualista" (MORAÑA, 1997, p. 21; tradução minha). ${ }^{15}$ Tendo em vista esta reflexão em torno à teoria do testimonio, é possível analisar a utilização da primeira pessoa do plural como uma estratégia narrativa de coletivização da experiência testemunhada, sendo esta explicada, em grande parte, pelo fato de Gavilán embasar seu relato em ações praticadas em conjunto - sejam elas no SL, no exército ou no convento franciscano.

\section{Considerações finais}

Como foi possível observar através deste breve trabalho de análise, o texto Memorias de un soldado desconocido é uma obra que logra articular o espaço de suas experiências (tempo passado), com o seu horizonte de expectativas (tempo por vir), ao mesmo tempo em que entrelaça essa tessitura de vida à sociedade e à história. Dito isso, é possível concluir-se, também, que a autobiografia de Gavilán é um bom exemplar do modo de vida moderno no qual, além do choque constante com as catástrofes, o sujeito está cada vez

\footnotetext{
15 "el yo-narrador surge en estos textos como una extensión de la colectividad y no como una sustitución de ésta, proponiendo una especie de totalidad sin centro. donde el individuo sobresale sólo por una operación estratégica de representación de acuerdo a los modelos del discurso narrativo occidental, a los cuales está siendo traducida una vivencia colectiva de carácter no-individualista" (MORAÑA: 1997, p. 21).
} 
menos veiculado a uma só trajetória. Transitando entre várias destas, ele conta com experiências tão diversas que contribuem ativamente na mudança das subjetividades. A esse respeito, torna-se válido afirmar que a memória subjetiva se constrói através de "interpretações" advindas de um conjunto de "estados passados impressivos", e este processo sempre se dá a partir do presente.

Como se discutiu a partir de Venera Alberti (1991) e Mabel Moraña (1997), por meio da obra analisada foi possível notar vários aspectos em comum entre autobiografia e testimonio, no que tange à representação do sujeito e às formas de figuração de si na modernidade. O testimonio, assim como a autobiografia, é uma vertente literária relativamente nova e, como é sugerido neste trabalho, merece ser estudada mais densamente, pois suscita muitas questões pertinentes aos estudos da memória, do testemunho e da literatura enquanto discurso não fechado em si mesmo. Enfim, vale ressaltar a importância de obras como a de Gavilán que propõe, a partir de uma síntese de suas memórias individuais, evidenciar a relação indissociável destas para com a memória coletiva.

\section{REFERÊNCIAS}

ALBERTI, Verena. Literatura e autobiografia: A questão do Sujeito na narrativa.

Estudos Históricos, Rio de Janeiro, v. 4, n. 7, pp. 66-81, 1991.

COSTA LIMA, Luiz. Júbilos e misérias do pequeno eu. In: COSTA LIMA, Luiz.

Sociedade e discurso ficcional. Rio de Janeiro, Guanabara, 1986, p. 40-56.

A construção social da memória moderna. Três ensaios sobre

Pessoa e modernidade. Boletim do Museu Nacional. Rio de Janeiro: Série Antropologia, pp. 28-54, 1983.

GALLE, Helmut. Elementos para uma nova abordagem da escritura autobiográfica. Matraga: Revista do Programa em Pós-Graduação em Letras / Universidade do Estado do Rio de Janeiro. Rio de Janeiro: UERJ, ano 13, n. 18, jan.-jun. 2006. 
GALLE, Helmut (et.al.) (org.). Em primeira pessoa: abordagens de uma teoria da autobiografia. São Paulo: Annablume; FAPESP; FFLCH-USP, 2009.

GAVILÁN, Lurgio, Memorias de un soldado desconocido. Autobiografía y antropología de la violencia. México: UIA/ IEP, 2012.

GINZBURG, Jaime. Impacto da violência e constituição do sujeito: um problema da teoria da autobiografia. In: GALLE, Helmut (et. al.) (org.). Em primeira pessoa: abordagens de uma teoria da autobiografia. São Paulo: Annablume; FAPESP; FFLCH-USP, 2009, pp. 123-131.

GOMES, Ângela de Castro; SCHMIDT, Benito Bisso (org.). Memórias e narrativas autobiográficas. Rio de Janeiro: Editora FGV, 2009.

HALBWACHS, Maurice. A memória coletiva. São Paulo: Vértice, 1990.

HINOJOSA, Iván. Sobre parientes pobres y nuevos ricos: las relaciones entre Sendero Luminoso y la izquierda radical peruana. In: STERN, Steve (ed.). Los senderos insólitos del Perú: Guerra y sociedad, 1980-1995. Lima: IEP/UNSCH, 1999, pp. 73-92.

LE GOFF, Jacques. História e Memória. Campinas: Editora da Unicamp, 1992.

LEJEUNE, Philippe. O pacto autobiográfico: de Rousseau à Internet. Trad. de Jovit Maria Gerheim Noronha e Maria Inês Coimbra Guedes, Belo Horizonte: Editora da UFMG, 2008.

MALLON, Florencia. ¿Crónica de un sendero anunciado? Velasco, Vanguardia Revolucionaria y "presagios luminosos" en las comunidades indígenas de Andahuaylas. In: STERN, Steve (ed.). Los senderos insólitos del Perú: Guerra y sociedad, 1980-1995. Lima: IEP/UNSCH, 1999, pp. 93-123.

MERCADO, Tununa. Testemunho, Verdade e literatura. In: GALLE, Helmut (et al.) (org.). Em primeira pessoa: abordagens de uma teoria da autobiografia. São Paulo: Annablume; FAPESP; FFLCH-USP, 2009, pp. 31-36.

MORAÑA, Mabel. Documentalismo y ficción: Testimonio y narrativa testimonial hispanoamericana en el siglo XX. In: MORAÑA, Mabel. Políticas de la escritura en America Latina: de la colonia a la Modernidad. Caracas: Ediciones e Xculturas, 1997, pp. 113-150. 
MOREIRAS, Alberto. A aura do testemunho. In: MOREIRAS, Alberto. A exaustão da diferença: a política dos estudos culturais latino americanos. Trad. Eliana Lourenço de Lima Reis e Gláucia Renate Gonçalves, Belo Horizonte: Ed. UFMG, 2001, pp. 249-282.

POLLAK, Michael. Memória e identidade social. Estudos Históricos, v. 5, n. 10, Rio de Janeiro, pp. 200-212, 1992. Disponível em: http://www.cpdoc.fgv.br/revista/arq/104.pdf; Acesso em: 08 jul. 2009.

SELIGMANN-SILVA, Márcio. "Zeugnis" e "Testimonio": um caso de intraduzibilidade entre conceitos. Letras, n. 22: "Literatura e Autoritarismo", Santa Maria, RS, pp. 121-130, jan./jun. 2001.

STERN, Steve (ed.). Los senderos insólitos del Perú: Guerra y sociedad, 1980-1995. Lima: IEP/UNSCH, 1999.

THEIDON, Kimberly. Entre Prójimos: El conflicto armado interno y la política de la reconciliación en el Perú. Lima: Instituto de Estudios Peruanos, 2004. 